\title{
Los orígenes de la Televisión Educativa en TVE (1958-1966)
}

\author{
Tamara ANTONA JiMENO \\ Universidad Complutense de Madrid \\ tamara.antona@ucm.es
}

Recibido: 04/02/2014

Aceptado: 10/03/2014

\section{Resumen}

Se analizan las primeras experiencias de la Televisión Educativa en nuestro país antes del inicio de Televisión Escolar. Por un lado se señalan cuales fueron los antecedentes directos, y por otro, se realiza una primera descripción de cómo eran esos programas y cual fue su presencia en las parrillas de programación. Palabras clave: Televisión Escolar, Televisión Educativa, Programación, Historia de la televisión en España.

\section{The origins of the educational television in Spain (1958-1966)}

\begin{abstract}
The goal of this paper is to analyze the first experiences Educational Television in Spain before the start of Television School. On one hand, which was the background indicate direct, and on the other hand, it makes an initial description of how these programs were and what was its presence in program schedules. Keywords: children's audience, youth audience, Spanish television, programming, program.

Referencia normalizada: ANTONA JIMENO, Tamara (2014): "Los orígenes de la Televisión Educativa en TVE (1958-1966)". Estudios sobre el Mensaje Periodístico, Vol. 20, Núm. especial, pp. 209-226. Madrid, Servicio de Publicaciones de la Universidad Complutense.

Sumario: 1. Introducción. 2. Metodología. 3. Relevancia de los programas educativos en la programación. 4. Los programas educativos emitidos en TVE desde 1958 a 1966. 5. Conclusiones. 6. Referencias.

\section{Introducción}

Informar, entretener y formar han sido los objetivos atribuidos a la televisión desde sus orígenes. Por ello, los programas que construyen el mensaje que emite responden, al menos, a una de estas funciones. Aquí se analizarán los primeros programas que se programaron en TVE con el fin de formar de manera explícita y directa: los programas educativos. Se ha acotado el objeto de estudio, las parrillas de programación, a las fechas comprendidas entre 1958 y 1966 . El inicio es obligado, puesto que no es posible realizar un estudio exhaustivo de las parrillas de programación antes de esta fecha ya que no se han conservado. La fecha final tiene una doble motivación. La primera es que en esa fecha comenzaron de forma regular las emisiones de la Segunda Cadena, por lo que para realizar un estudio pormenorizado de la Televisión Educativa se deberían incluir también sus emisiones. El segundo motivo es que en la temporada 1967-1968' comenzó a emitirse el programa Televisión Escolar, que puede considerarse la primera emisión en la que se impartía docencia de forma reglada y de acuerdo con el Ministerio de Educación.
\end{abstract}

1 Aunque las emisiones estaban previstas para octubre de 1967, el programa Televisión Escolar no arrancó hasta enero de 1968 (Baguet, 1992). 
El objetivo de principal de este artículo es analizar el origen de los programas educativos en la televisión española y saber si existen antecedentes directos del proyecto Televisión Escolar. Para ello, y dada la ambigüedad a la que puede dar lugar el término 'educativo', se necesita una definición precisa de lo que se han considerado programas educativos.

La autora Marta Serrano refleja el hecho de que siempre que se ha tratado de definir el concepto de Televisión Educativa, han surgido "los clásicos enfoques que la vinculan tanto en sus áreas de actuación, uso o aplicación para los distintos niveles escolares (desde preescolar hasta posgrado), así como dentro de los distintos modelos educativos (sean conductistas, cognitivos o constructivistas), pero, sobre todo, para las modalidades de enseñanza formal reglada (sea presencial, abierta o a distancia), o bien, no reglada o informal" (Serrano, 2008: 3). Es a partir de esta diversidad de enfoques de dónde procede la doble concepción de la Televisión Educativa: por un lado, una televisión escolar, pedagógica, didáctica y, por otro lado, la televisión cultural, divulgativa o de conocimiento. Ahondando un poco más en las definiciones de Televisión Educativa, encontramos que diferentes autores han considerado que ${ }^{2}$ bajo la denominación de Televisión Educativa pueden incluirse tres tipos de programas ${ }^{3}$ : los culturales, los escolares y los educativos.

Los programas que están dentro del primer grupo, al que se puede denominar Televisión Cultural, estarían a medio camino entre la divulgación y el entretenimiento y son por ejemplo, los documentales. Por su parte, en la Televisión Educativa el objetivo principal es el de formar, pero desde una forma externa al sistema educativo aunque con contenidos propios del mismo. Es decir, dentro de Televisión Educativa encontraremos programas que tienen como misión principal la transmisión de conocimientos y que el espectador, además de entretenerse, aprenda.

Los programas que se agrupan dentro de Televisión Escolar son aquellos que imparten desde las ondas lecciones regladas. En otros países como Estados Unidos, Gran

${ }^{2}$ Según indica Julio Cabrero en su artículo La Televisión Educativa: aspectos a contemplar para su integración curricular: "como han puesto de manifiesto diferentes autores (Clermont, 1992; Martínez, 1992; Tiene, 1994) bajo la denominación genérica de Televisión Educativa, se pueden incluir tres tipos diferentes: cultural, educativa y escolar: a) la televisión cultural, es la más genérica y se marca como objetivos prioritarios la divulgación y el entretenimiento, encontrándose el planteamiento educativo inmerso dentro del propio programa no requiriendo por tanto de materiales complementarios [...]; b) la Televisión Educativa, contempla contenidos que tienen algún tipo de interés formativo y/o educativo, pero que por algún motivo no forman parte del sistema escolar formal, [...] empieza a adquirir sus bases de diseño de la didáctica y teorías del aprendizaje, frente al carácter divulgativo y de entretenimiento del tipo de televisión anterior, la presente persigue influir en el conocimiento, las actitudes y los valores del espectador; c) y la televisión escolar, que persigue la función básica de suplantar al sistema escolar formal” (Cabrero, 1994:3-4).

${ }^{3}$ En el Informe Marco de la Televisión Educativa en España elaborado por el Ministerio de Educación en el año 1996, recoge un cuarto grupo de programas educativos integrados por aquellos que "no tienen explícitamente intencionalidad educativa, pero que por sus contenidos, o por su pertenencia a determinados géneros y formatos audiovisuales, ejercen, de hecho, una influencia educativa relevante en positivo o en negativo", como podrían ser ficciones de producción propia que hablen o describan determinados estereotipos. 
Bretaña, Francia o Méjico, estos espacios se han desarrollado con un claro objetivo pedagógico impulsado desde las cadenas y/o Gobiernos ${ }^{4}$, pero en España han tenido muy poco calado. El primer programa de este tipo que hubo en España fue un proyecto que arrancó en 1968: Televisión Escolar. La primera emisión tuvo lugar el 29 de enero de 1968 y fue un programa planteado de acuerdo a los criterios del Ministerio de Educación Nacional y de la que fue responsable, como apunta Baguet, Jesús García Jiménez ${ }^{5}$, director de las comisiones asesoras de programas educativos: "Una comisión especial mixta formada por representantes del ministerio de Educación y de TVE se encargó de fijar las materias a impartir, aunque algunas quedaron fuera de su órbita: la formación religiosa dependía de la Comisión Episcopal de Enseñanza y la formación cívico-social y la educación física dependían de las Delegaciones Nacionales de Juventudes y la Sección Femenina" (Baguet, 1992:190).

Este estudio pretende arrojar un poco de luz sobre los orígenes de la Televisión Educativa en España, entendiendo como Televisión Educativa todo aquel programa cuyo objetivo principal era el de impartir conocimiento a la audiencia, la transmisión de información frente al entretenimiento, con contenidos enmarcados dentro de las áreas de conocimiento académico. Una de las hipótesis de las que partimos es que estos programas no sólo estaban dedicados al público más joven, sino que, dada la coyuntura nacional en la que una parte de la población no tuvo la oportunidad de ir a la escuela o si fue, lo hizo durante muy poco tiempo, también estaban destinados a que los adultos tuvieran acceso a la cultura (según datos de los censos de la época, se estima que un 25 por ciento de la población no sabía ni leer ni escribir ${ }^{6}$. Con esto no se pretende decir que el objetivo de TVE era el de alfabetizar ${ }^{7}$ a la población iletrada, sino que más bien al ser una emisión generalista y cómo parte del carácter pedagógico del modelo público de televisión, era una consecuencia natural, y como ello fue asumida por los responsables de la cadena.

El acercamiento que se hace a la historia de la televisión en este artículo es novedoso: la aproximación a través de las parrillas de programación. Numerosos autores han abordado la historia de la televisión en nuestro país. El 50 aniversario de TVE ini-

4 Según datos del Informe Marco de la Televisión Educativa en España (1996), “en Estados Unidos, el Sistema Público de Televisión, Public Broacasting Sistem (PBS), cuenta con un presupuesto anual de unos 165.600 millones de pesetas; en el Reino Unido, la cadena pública British Broadcasting Corporation (BBC) destina al ámbito educativo un presupuesto anual de unos 9.660 millones de pesetas y su competidor privado, Channel 4 TV, unos 5.460 millones. Una televisión regional canadiense como TV Ontario dedica anualmente casi 6.882 millones de pesetas a su producción educativa. La cadena educativa que más recientemente ha iniciado sus emisiones, en diciembre de 1994, La Cinquième francesa, lo ha hecho con un presupuesto anual de unos 18.200 millones de pesetas".

5 Autor de Radiotelevisión y política cultural en el Franquismo, 1980.

${ }^{6}$ Los datos recogen que de los 30.528.539 habitantes censados, 7.647.365 eran analfabetos en 1960, 3.239.173 hombres y 4.408.195 mujeres. En, de Gabriel, 1997.

7 La acepción de "alfabetizar" como "Enseñar a leer y escribir a los analfabetos de un país" no se incluiría en la RAE hasta 1970. En Viñao, 2009. 
ció un proceso de revisión histórica sobre el medio y un intento de recuperación de la memoria televisiva española ${ }^{8}$. En general, los autores que se han ocupado de la historia de la televisión en España han abordado su desarrollo ${ }^{9}$ y las características fundamentales ${ }^{10}$. También hay estudios culturales sobre la relación del medio con el sistema de gobierno ${ }^{11}$, o sobre los contenidos que se emitían ${ }^{12}$ y también sobre la recepción ${ }^{13}$. Sólo hay un par de autoras que se han acercado a la televisión por medio de las rejillas: Gloria Gómez Escalonilla y Natividad Carreras Lario ${ }^{14}$.

Respecto al estudio de los programas educativos, salvo algunas referencias genéricas en los libros que hablan sobre la historia de los programas y alguna mención en trabajos académicos sobre televisión y pedagogía o Televisión Educativa ${ }^{15}$, no hay mucho escrito, por lo que este artículo tratará de llenar ese vacío ${ }^{16}$.

8 Aquí son destacables los esfuerzos de Bustamante Rueda y Chicharro, Gutiérrez, o Díaz. Todas estas iniciativas se unían a la labor realizada en los años noventa por investigadores como Palacio.

9 Manuel Palacio y también Josep Ma Baguet i Herms, Nacho Rodríguez Márquez, etc.

${ }^{10}$ Jesús Timoteo Álvarez, Pérez Ornia, Arranz Ayuso, etc.

${ }^{11}$ Sanz Méndez, Moya o Rueda Laffond

${ }^{12}$ García Castro, Ibáñez o el mismo Palacio

${ }^{13}$ Desde los trabajos de Charo Lacalle, sobre el espectador, a diversos artículos basados en los intentos de la época en evaluar lo que les gustaba a las audiencias, como las encuestas del diario Pueblo (hacia 1961) o más adelante, con el IOP

${ }^{14}$ La primera habla de la programación a lo largo de 40 años y la explica por motivos políticos de carácter general, no por causas de TVE, además de no profundizar en el análisis. La segunda habla de la programación de TVE pero sólo hasta 1962, aunque se limita a la mera descripción.

${ }^{15}$ Con autores como Jesús Cabrero

${ }^{16}$ La primera de las obras que cabe mencionar dentro de los estudios de televisión educativa en España es la tesis doctoral de Justo Merino Belmonte guionista en Imágenes para saber. $\mathrm{Su}$ obra es de obligada referencia para hablar de la Televisión Educativa en España pues hace un recorrido, desde el punto de vista de alguien vinculado al medio, por todos los programas que TVE puso en marcha en el terreno educativo. Para ello el autor recurre a su propia memoria y a las "escasas fuentes históricas"; como asegura en la introducción. Merino realiza un análisis exhaustivo de las noticias aparecidas en los Telediario y Tele Radio desde 1958. Aunque se trata de un recurso muy sólido, el inconveniente es que todos los programas de los que Merino habla difícilmente podrían categorizarse hoy como educativos. Es explicable porque el planteamiento que el autor hace acerca de este tipo de programas es el de la revisión histórica de TVE, a fin de establecer unos antecedentes y elaborar así un modelo de Televisión Educativa que, como ya se ha mencionado, a diferencia de otros países en España no llegó a calar. Otra de las obras de obligada cita es Radiotelevisión y política cultural en el Franquismo, del que fuera Director de las comisiones asesoras de programas educativos, anteriormente mencionado: Jesús García Jiménez, que realiza un planteamiento bastante crítico con las experiencias realizadas y hace un recorrido basado la perspectiva política. Por último caben destacar La educación por televisión y Dimensión y sistema de la televisión educativa, ambos de Joaquín de Aguilera hace una revisión histórica bastante somera que hace de los programas educativos y centrada en Televisión Escolar (1968-70). 


\section{Metodología}

Este estudio pretende recabar toda la información relevante acerca de los orígenes de la Televisión Educativa en España antes del lanzamiento de la experiencia piloto que se hizo en nuestro país en el año 1968 y que llevó por nombre Televisión Escolar. La metodología utilizada para este estudio será doble. En un primer momento abordaremos los programas como parte de la parrilla de programación. Para ello, se procederá al análisis de las rejillas. Se han utilizado los datos registrados en la base de datos elaborada para la tesis doctoral (en curso) La televisión de una audiencia cautiva: historia de la programación en el franquismo ${ }^{17}$. Este estudio pretende ser uno de los primeros resultados obtenidos de la utilización de esta herramienta.

En la base de datos se han registrado exhaustivamente todas las emisiones de TVE desde enero de 1958 a noviembre de $1975^{18}$, aunque para este artículo se utilizarán únicamente las emisiones comprendidas entre 1958 y 1966. En esta herramienta han quedado reflejados dos tipos de información: por un lado, datos relativos a la descripción las emisiones (bloque de programa, tipo de programa, equipo técnico, etc.); y por otro, un registro pormenorizado de los programas (fecha, hora de inicio, hora de fin, duración, etc.). En el análisis descriptivo de las emisiones categorizadas como Bloque: Divulgativo - Tipo de programa: Educativo se han considerado todos los programas que tenían como objetivo la divulgación del conocimiento de forma directa. Por ejemplo, el caso de Aula TV en el que un profesor impartía lecciones de una cuestión específica, o Universidad $T V$ en el que un catedrático daba un monográfico sobre una materia determinada. No están incluidos ni documentales, que tienen su propio subgénero, ni los programas en los que se divulgaban conocimientos que hoy en día quedarían fuera de la enseñanza reglada: aquellos en los que coser o aprender a quitar manchas de grasa eran el objetivo. El tipo de programa Educativo está referido, como avanzábamos en el anterior punto, a las materias básicas que componen el conocimiento académico: geografía e historia, lengua, literatura, filosofía, matemáticas, ciencias, lenguas extranjeras y programas que estén relacionados con el desarrollo de la infancia y la juventud. Todo lo demás ha sido clasificado como entretenimiento.

La segunda parte de la metodología inicialmente se basaba en el análisis de los programas y para ello se quiso acudir a la fuente primaria: el archivo de RTVE. Para ello se elaboró un listado con todos los programas de divulgación enmarcados dentro del tipo de programa Educativo: en total 20 programas diferentes emitidos entre 1958

${ }^{17}$ Tanto la tesis como esta investigación están enmarcadas en el proyecto financiado por el Ministerio de Educación: Televisión y Cultura popular durante el franquismo: Programación, programas y consumo televisivo (1956-1975), ref. HAR2011-27937

${ }^{18}$ Cada emisión es una entrada en la base de datos y para que el margen de error sea el menor posible se han contrastado de tres fuentes diferentes: ABC, La Vanguardia y Tele Radio. Somos conscientes de que puede que lo que reflejan las fuentes hemerográficas no sea exactamente lo que se emitió en TVE debido a diferentes causas como eventos de última hora, fallos de cálculo en la planificación de los programas en directo o por erratas de las fuentes, pero entendemos que esos errores son perfectamente asumibles dado el volumen de información con la que se ha trabajado. 
y 1966. Una vez obtenido, se cursó la petición al archivo de RTVE para proceder al visionado y realizar un análisis de, al menos un ejemplo de cada uno de ellos. La respuesta fue que de estos 20, en ARCA, la base de datos de fondos audiovisuales ${ }^{19}$, no se ha encontrado información de ninguno de ellos. En cambio sí que se ha recuperado un fragmento del programa Jardilín ${ }^{20} \mathrm{y}$ dos fragmentos del 1 de enero del 1970 del programa Televisión Escolar ${ }^{21}$ :

Dada la imposibilidad de visionar los programas educativos, se ha optado por realizar una revisión de las fuentes hemerográficas, en concreto de la revista Tele Radio y su antecesora Telediario para tratar de describir el formato de estos programas e inferir el público al que estaban destinados, así como evaluar cuán educativos se pueden considerar.

\section{Relevancia de los programas educativos en la programación}

La primera aproximación que se ha hecho a los resultados es desde el punto de vista cuantitativo: se ha realizado un estudio de las horas de programación de la Televisión Educativa en los diferentes años del periodo estudiado y también se establecerá qué porcentaje del total de programación de TVE estaba destinado a este tipo de emisiones.

Para el primero de ellos, se ha elaborado este gráfico a partir de la suma del total de horas emitidas entre 1958 y 1966. En él, puede apreciarse que entre 1962 y 1964 es el momento en el que más horas se dedicó en TVE a este tipo de contenidos, mientras que 1959, 1958 y 1965, por ese orden son los años en los que menos horas de programación estuvieron dedicadas a la educación.

${ }^{19}$ De acceso exclusivo para el personal de RTVE.

${ }^{20}$ A diferencia de los documentalistas de TVE nosotros lo clasificamos como infantil, no como educativo, de hecho en sus investigaciones María Antonia Paz y Lizette Martínez lo tratan como programa puramente infantil. La información que conserva TVE es la siguiente: "Serie dedicada a los niños de edad preescolar y a las madres. Los programas son conducidos por una presentadora, que ejerce el papel de profesora de jardín de infancia, a la que acompañan seis niños y niñas de entre cuatro y cinco años de edad. Romper Room es un programa que se emite en quince países entre ellos, España, aquí con el nombre de Jardilín, el cuarto de los niños. El programa nació en EEUU quince años antes y después ha ido extendiéndose a otros países, en todos ellos se mantiene una construcción formal, idéntica pero en casa uno de ellos se ajusta a las costumbres, tradiciones y modos de ser propios. En todos los países lo rige una presentadora (la maestra) y colaboran con ella seis niños y niñas de cuatro a cinco años que van cambiando en el transcurso de las semanas. Fuente: Tele Radio del 17 al 23 de octubre de 1966, sin paginar).

${ }^{21}$ Dada la fecha quedaría fuera de nuestro estudio, además, como adjuntamos a continuación, la información conservada sería no obstante insuficiente para el análisis a través del visionado: - PL. La presentadora hablando del libro de inglés y despidiendo el programa. Cabecera de salida y títulos de crédito. Negro y fin de programa.

- PL. Fragmento de uno de los contenidos de una sección de Televisión Escolar dónde Rodríguez de la Torre (director de un colegio) habla de la televisión como vehículo de enseñanza (voz en off. Pregunta). Negro y fin cinta. 
Gráfico 1: Evolución de los contenidos educativos de TVE en horas y minutos (1958-1966)

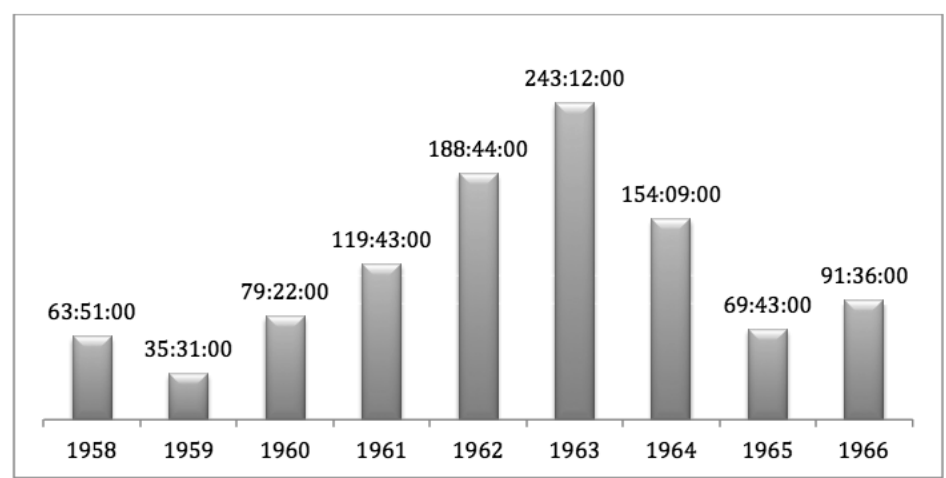

Fuente: ABC, La Vanguardia, Telediario y Tele Radio. Elaboración propia.

En cuanto al porcentaje respecto al total de emisiones que ocupa la Televisión Educativa, se observa que en ningún momento del periodo estudiado se supera el 7 por ciento. En 1963 se localiza la presencia más fuerte con un 6,16 por ciento del total de programas dedicados a la educación, mientras que en 1959 y 1965 se encuentra que tan sólo el 1,74 y el 1,66 por ciento se dedicaban a estos contenidos. Las cifras coinciden con las estimaciones respecto a las horas, salvo en 1958 pero la explicación es que aunque se emitieron menos horas de Televisión Educativa, las horas totales de programación eran menores, por ello duplica la presencia de este tipo de programas respecto al año siguiente: aunque las horas son menos, respecto al total de la programación tiene más presencia.

Gráfico 2: Porcentaje del espacio de emisiones dedicado a Televisión Educativa en TVE (1958-1966)

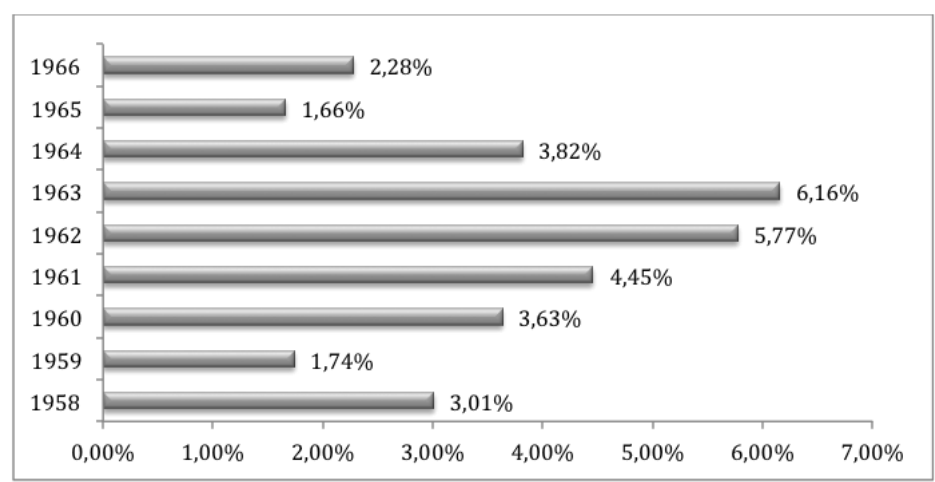

Fuente: ABC, La Vanguardia, Telediario y Tele Radio. Elaboración propia.

La conclusión es que la media de tiempo del total de programación destinado a los contenidos educativos en el periodo estudiado se sitúa en torno al 3 por ciento del total de las emisiones. Es decir, muy poca presencia en términos generales. 


\section{Los programas educativos emitidos por TVE desde 1958 a 1966}

En este punto se tratarán de analizar los programas concretos referidos a la Televisión Educativa. Lo primero que se hizo fue localizar el listado de programas clasificados como Divulgativo-Educativos: un total de 20 programas, y realizar una tabla con ellos en la que se reflejara la franja horaria ${ }^{22}$ en la que fueron emitidos así como la duración en horas-minutos totales de sus emisiones. El resultado fue que en 1958 aparecen un toral de siete programas diferentes: Aula TV, Lección de Inglés, Lección de Francés, Inglés para todos, Francés para todos, Curso de Inglés y Curso de Francés. Es decir: un programa que en principio parece generalista o un espacio 'contenedor' y programas de idiomas. Si se atiende a su colocación en parrilla y a su duración y frecuencia observamos que Aula TV dura escasos 2 ó 3 minutos, por lo que se puede pensar que en una lección muy breve de alguna materia general o lo que es más probable: una presentación de los programas que van a continuación, por lo que se puede intuir que Aula TV es la entrada a la programación que en TVE consideraban de corte pedagógico. En cuanto a la franja oscila en la de tarde noche, pero en todos los casos aparece después de los programas dirigidos al público infantil y en la mayoría de los casos tras un cierre de las emisiones. Es decir: no hay continuidad en la programación de tarde por lo que es fácil pensar que el público al que van dirigidos estos programas, a pesar de que en ocasiones están situados en esta franja es diferente al de la franja de tarde. Aula $T V$ se emite de lunes a sábado y el programa que sigue inmediatamente es diferente cada día de la semana y va cambiando a lo largo del año, pero en general son programas que podemos clasificar 'de servicio' o de 'entretenimiento útil': Decoración, Orientación profesional, Charlas de puericultura, Revista de Aviación o Juegue usted con nosotros son algunos ejemplos. Después de estos, aparece otro educativo: una lección de idiomas (inglés o francés) que aunque va cambiando de nombre a lo largo del año es el mismo. Se ha localizado en el primer número de la revista Telediario (número 1, del 31 de diciembre de 1957, sin paginar) la siguiente declaración de intenciones:

"Es propósito reservar en estas columnas un espacio dedicado a ser un complemento de las clases de francés e inglés que se transmiten en la semana. De esta manera esperamos que los telespectadores puedan seguir citadas clases con el mayor provecho, permitiéndoles al mismo tiempo conocer de antemano los temas que se transmitan a lo largo de la semana siguiente. Aceptaremos cualquier sugerencia que se nos haga sobre el particular, ya que nuestro mayor deseo es conseguir mayor eficiencia de las lecciones" (Revista Telediario, primer número, 31 de diciembre de 1957).

${ }^{22}$ El día lo hemos dividido en cuatro franjas: mañana, mediodía tarde y noche. El inicio de la franja de mañana se ha definido para los programas que comenzaran antes de las 12:00. El inicio del mediodía se fijó en el primer programa emitido más allá de las 12:00 y finaliza en la programación infantil: las 17:00. La tarde la hemos clasificado estableciéndola en fin de la programación de mediodía hasta el fin de la programación infantil o el comienzo del Telediario (20:30 horas). La noche comienza con el noticiario y finaliza en el Cierre de emisión. Tendrían igualmente la condición de nocturnos aquellos programas, si los hubiera, que se emitieran antes de las 6 am. 
En este número y en los posteriores (entre enero y diciembre de 1958) encontramos que, estos cursos estaban creados por en Instituto Mangold, y las diferentes lecciones que se impartirían lo largo de la semana de los dos idiomas: el Curso de Francés que se emitía los martes jueves y sábados a las 21 horas; y el Curso de Inglés, los lunes, miércoles y viernes a las 21 horas. Merece especial atención al anuncio del Instituto Mangold publicado en el número 14 de Telediario (del 31 de marzo de 1958, sin paginar) y que se repetiría a lo largo de las semanas en el que se pedía opinión a los espectadores acerca de los cursos. En el número 53 del 29 de diciembre de 1958 (sin paginar), aparece una felicitación de Año Nuevo del Instituto en el que hace una serie de consideraciones dignas de mencionar por su relevancia a la hora de tratar de reconstruir estos programas de idiomas:

"España es el primer país que ha empleado la pantalla de TV para ofrecer a los telespectadores un curso lingüístico, es decir, no de mero entretenimiento, sino con base didáctica [...]. "El problema que se nos había presentado en este nuevo medio, primordialmente plástico y visual, era el de interesar a TODOS los espectadores, lo mismo a los que sólo tienen unos conocimientos rudimentarios de la lengua que a los que quieran perfeccionar unos conocimientos ya adquiridos. [...] No obstante, los testimonios favorables y hasta entusiastas que hemos recibido de la mayoría de los telespectadores creemos que es nuestro deber ahora renunciar a un éxito fácil a costa de nuestra misión didáctica. Ya ha llegado el momento de pedir a los que tienen conocimientos bastante amplios del inglés o el francés una concesión a favor de los muchos, sobre todo jóvenes, que están todavía en etapa de aprendizaje, en los colegios o institutos, para ayudarles en sus estudios más elementales" (Revista Telediario, $\mathrm{n}^{\circ}$ 53, 29 de diciembre de 1958).

Merino asegura que "sin entrar a discutir si el Instituto tiene razón o no al afirmar que España es el primer país en programar este tipo de espacios, se trata de una experiencia "bastante reciente" que constituye una auténtica novedad. Sobre estos programas se refiere también Baguet asegurando que gozaron de una rápida popularidad y que por ello ocupaban este horario. Además aporta el dato de que se ilustraba con películas obtenidas a través del mismo instituto o de las embajadas (1992:32).

El último programa educativo que encontramos en 1958 se sitúa entre junio y julio: una emisión llamada Televisión Escolar, de una hora de duración en la franja de noche (entre las 20:30 y las 21:30h). De vida corta (sólo un par de emisiones) se extinguiría de la pantalla para regresar 10 años después. No hay referencias acerca de qué contenía, aunque en el Telediario número 29, del 14 de junio de 1958 (sin paginar) encontramos bajo su anuncio de emisión la siguiente descripción: "Programa para niños en colaboración con la Biblioteca de Iniciación Cultural de la Comisaría de Extensión Cultural".

En 1959 se mantiene Aula TV seguida de los mismos programas que mencionábamos anteriormente, pero desaparecen por completo las lecciones de inglés, y el francés se reduce a una vez por semana aunque duplicando su duración: el programa Lecciones de Francés desaparece, con una duración de 15 minutos durará hasta marzo en parrilla, fecha en la que dejan de emitirse también las guías de idioma en Telediario. Hasta marzo, este programa estará seguido por los documentales Nos llega de... (Francia los lunes, Italia los martes, Inglaterra los miércoles, USA los jueves y Alemania los viernes) con una duración de 30 minutos aproximadamente. Este programa 
estará en parrilla hasta marzo. A partir de este mes no encontramos ningún programa educativo más en el año 1959 hasta noviembre, fecha en la que comienza a emitirse Universidad TV de lunes a jueves de 20:00 a 21:00 horas. Este espacio será obre personal de Luis de Sosa, según Baguet, y tendrá una vida en la parrilla tan larga como le permitió al impulsor del mismo su salud (1992:67). Dada la descripción que hace este autor de los invitados del programa parece que consistía en lecciones magistrales de expertos sobre temas como las matemáticas, la física, la historia de España, temas bíblicos o de biología impartidos por profesores especialistas en las materias y poco a poco fueron incorporándose otros profesionales que permanecían vinculados a TVE en otros programas ${ }^{23}$.

Según las referencias encontradas en Telediario sobre Universidad TV, parece que la idea de que los catedráticos estuvieran en el salón de cada uno de los alumnos interesados les parecía magnífica (entrevista a Luis de Sosa publicada en el Telediario del 2 de noviembre de 1959, página 5), de hecho se publicita con bastante entusiasmo en las páginas de la revista: "Los temas científicos de mayor actualidad en nuestras vidas merecerán especial atención" además de "Un sistema de becas facilitará la asistencia personal a las clases". Como señala Merino, el "batiburrillo que representaba el intento" de llevar la universidad a cada hogar desde materias tan dispares, a priori parece "difícil de coordinar y más difícil aún de seguir". Además, el autor señala, que a pesar de las ganas que los catedráticos ponían en este experimento, "no acertaron a comprender que, sin el empleo de un auténtico lenguaje televisivo, cualquier experiencia educadora por este medio está irremisiblemente abocada al fracaso". Con motivo del cuarto aniversario de Universidad $T V$ aparece un reportaje publicado en el Tele Radio número 256, del 19 de noviembre de 1963, páginas 19-25, en el que se plantea que:

"Universidad TV no ha sido entendida como negocio, sino como un acto de servicio.

Esto explica que TVE haya triunfado en una empresa considerada como imposible en el mundo entero. Más de cien catedráticos de universidad atienden a los distintos cursos... y las numerosas consultas de los espectadores" (Revista Tele Radio, $n^{\circ} 256,19$ de noviembre de 1963, pp. 19-25).

Además, a lo largo del reportaje se destaca que en los cuatro años que han durado las emisiones se ha aumentado el claustro de profesores a más de cien, casi todos ellos catedráticos de universidad, y se remarca lo siguiente:

"Un programa de esta envergadura no se concibe sin un bien estudiado plan. Universidad $T V$ lo tiene. De las cosas que interesan al público se han hecho dos grupos. En uno se ha incluido todo aquello que, por formar parte de la cultura, constituye el andamiaje de la formación del individuo. En el otro grupo se insertan las cuestiones que, por ofrecer un in-

${ }^{23}$ Baguet señala que entre los profesores que Luis de Sosa "había persuadido para que se integraran en el programa figuraron de entrada Luis Morales Oliver (novela española), Ángel Vegas (matemáticas), Luis Bru (iniciación a la física), Joaquín Sánchez Cordovés (electrónica), Tomás Alviria (Biología) y Salvador Muñoz (temas bíblicos) mientras que el propio Sosa trataba temas de historia de España” (67:1992). 
terés actual, bien sea nacional o universal, requieren ser tratadas por expertos" (Revista Tele Radio, $n^{\circ}$ 256, 19 de noviembre de 1963, pp. 19-25).

Dicho de otro modo: desde la dirección aseguran que existe un cuidado plan de estudios en el que se incluyen temas de interés general y temas que por una determinada razón son de interés público por su repercusión actual. Para el primero pone el ejemplo de un programa en el que intervienen los catedráticos Morales Olivier y Muñoz Alonso sobre Menéndez Pelayo, por un lado. Para el otro tipo de temáticas, lo ejemplifica con el caso del medicamento Talidomida ${ }^{24}$, que será presentado por el profesor García Orcoyen. En el reportaje se deshacen en alabanzas a este programa asegurando que numerosos ("cientos, miles incluso millones") se sientan delante del televisor para disfrutar del programa, el cual han considerado en Tele Radio "La Universidad más barata del mundo".

En 1960 Aula TV se dota de contenido pues aumenta su duración: llegará hasta casi la media hora de lunes a viernes entre las 20:30 y las 21 horas, mientras que Universidad $T V$ se relegará a lo jueves y reducirá su duración a la mitad en horario de 19:30 a 20:00 hasta octubre de ese mismo año que volverá a ser diario aunque sólo recuperará su duración original de una hora los jueves y se prolongarán durante el curso académico siguiente (hasta junio de 1961). A diferencia de las dos anteriores temporadas, estas emisiones están enmarcadas fundamentalmente en el horario de tarde casi sin corte detrás de la programación infantil y juvenil por lo que son parecen ser los destinatarios naturales de estos programas. En julio de 1961 se introduce un programa nuevo Escuela TV, que a partir de septiembre coexistirá con Universidad TV en la franja de tarde.

Escuela $T V$ era una experiencia piloto que comenzó en verano precisamente para ensayar, para que en octubre, con el inicio del nuevo curso académico arrancar además con más asuntos relacionados con el mundo profesional, es decir, pretendían impartir cursos sobre cómo ser fontanero o tornero fresador. En el reportaje publicado en el Tele Radio número 188, página 13, con motivo del inicio de las emisiones en julio de 1961 se plantea que se trata de un programa creado por ocho guionistas "jóvenes de sólida formación intelectual y universitaria".

En el trabajo de Jesús Merino puede encontrarse una amplia descripción de los que fue el programa, aunque caben destacar dos cuestiones: la primera es que en ningún momento se pensó desde TVE que este programa cumplía la función de sustitución o complemento de la escuela tradicional, de hecho el propio director, Manuel Summers, asegura en la declaración de intenciones publicada en el mismo Tele Radio anteriormente citado que este programa "de tipo educativo, ameno, ligero, atractivo, simpáticos [...] para despertar en ellos (los niños) el afán de aprender". Esta iniciativa responde más bien a la atención hacia un tipo de audiencia que además de entrete-

${ }^{24}$ Medicamento comercializado entre 1985 y 1963 como sedante o calmante de las náuseas de los primeros meses del embarazo que fue responsable de numerosas malformaciones congénitas. 
nerse con programas de variedades y entretenimiento, demanda contenidos más estimulantes intelectualmente hablando (Merino, 1982:113). La segunda cuestión que hay que recoger acerca de la Escuela TV es en su evolución hacia unos contenidos más profesionales. Como destaca Justo Merino, las familias que en 1961 tenían la capacidad de adquirir un receptor de televisión, no tenían la intención de que sus hijos se dedicaran en el futuro a estas cuestiones.

A estas dos reflexiones, faltaría añadir la tercera: a pesar de que desde TVE se pensase en la infancia como la audiencia objetivo, y que por ello estuviera situado en la parrilla en franja de tarde, el hecho es que no hay ningún estudio que demuestre que efectivamente fue así, y por las materias impartidas estos programas podían interesar perfectamente a mentes inquietas, independientemente de su edad.

Tanto los ya mencionados Escuela TV y Aula TV como Academia TV eran espacios propios de TVE, sin conexión de ningún tipo con el Ministerio de Educación Nacional, denominados así por el contenido instructivo que les caracterizaba. En palabras de García Jiménez: "se llamaban así únicamente por extensión, puesto que ni su estructura, ni su funcionamiento, ni su insolidaridad con el sistema educativo propiamente tal, ni sus métodos en la recepción y explotación del mensaje, ni el personal docente que intervenía en ellos, ni el anonimato del público en general y heterogéneo que se limitaba pasivamente a recibirlos como un programa más, ni su falta de utilidad práctica a efectos de validez académica, autorizaban a considerarlos en rigor verdadera televisión educativa" (en Baguet, 1992:109).

Academia $T V$ era un programa contenedor en el que, como se recoge en el número 303 de Tele Radio, sin paginar:

"Programa de presentación con exposición de todos los espacios de Academia TV: Inglés para todos, Artes Plásticas, Divulgación Médica (primeros auxilios), Preliminar (Formación Preliminar), Secretariado (taquigrafía y mecanografía), Artesanía en pantalla (trabajos y labores), Formación cívica, Automóvil y circulación, Ciencia Española (sobre la labor del CSIC), Reportaje de la Cultura (documentales de la URI), Números (resolución de problemas matemáticos), Interpretación musical (la guitarra), El mundo de las alas (aviación) Paso de danza (ballet), Ciencia en imágenes (Documentales educativos), Orientación profesional, Hablar y Escribir (lengua española), Organización de Empresas, La Nueva Geografía (nuevos Estados), Iniciación a la música (cultura musical), La Mar (divulgación marinera) y Foto-cine" (Revista Tele Radio, n 303, 14-20 de octubre de 1963).

Se trataba de un espacio creado por Rafael Martín, de "muy amplio espectro de temas tratados de forma un tanto asimétrica" (Baguet, 1992:109) que se incorporaría a la parrilla diaria de los días laborables en 1962, en franja de tarde con 45 minutos de duración. Este es el único programa con el que se ha hecho una excepción a la definición que inicialmente se dio para referirnos a televisión educativa, porque, debido a que en las fuentes hemerográficas no está nada claro lo que se emitía cada día no se han podido clasificar por separado los espacios, por lo que todos han sido categorizados como Televisión Educativa.

En el Tele Radio número 257, del 26 de noviembre de 1962, página 29, se publica un artículo en el que se hace una mención especial al público que compone este programa y su contenido, haciendo especial referencia a que, aunque nació como pro- 
grama de pretendida educación, a lo largo de los meses tenían la intención de que evolucionara a contenidos más divulgativos, propios del medio con diferentes filmaciones que se irán incorporando. La característica principal que se destaca en este artículo sobre Academia TV, que "ha conseguido ocupar el espacio entre Escuela TV y Universidad $T V$ " es la de dirigirse a un público heterogéneo en su procedencia pero que no tiene acceso a la educación. Tanto la original idea de que fuera un programa educativo, como esta última afirmación son las dos razones por las que en este estudio se ha considerado Academia TV como programación educativa.

En octubre de 1962 se recuperan los cursos de idiomas, tanto de inglés como de francés en la franja de tarde, sobre las 19:00 horas y con una duración de 30 minutos. La programación educativa continuará así todo el curso 1962-1963 hasta verano, en el que finalizan este tipo de emisiones.

En octubre del año siguiente, 1963, comienza a emitirse Bachillerato TV: una experiencia completamente diferente. Bachillerato $T V$ tenía la misión de complementar el Bachillerato Radiofónico, inaugurado el 8 de febrero de ese mismo año, y además de los programas emitidos se publicaba una revista con 30.000 ejemplares de tirada. Se trata del primer programa de televisión en el que se impartieron lecciones de dibujo, Ciencias Naturales, Matemáticas, Geografía, Música, Literatura y Religión de forma sistemática y de pleno acuerdo con el Ministerio de Educación Nacional. Un Centro Nacional de Enseñanza Media por Radio y Televisión se encargaba de la ejecución del programa y su director, Luis Ortíz Muñoz, era catedrático y director del Instituto Ramiro de Maeztu de Madrid (Baguet, 1992:127).

Con la incorporación de Bachillerato TV, la programación de la franja de tarde estaba copada por programas educativos entre las 18:00 y las 19:30 horas. Una hora y media de programación enmarcada en la franja de tarde, dedicada al público más joven, por lo que sí que parece claro que estos programas parecían tener la misión de reforzar a los niños, jóvenes en su tareas escolares diarias. Aunque con el caso específico de Bachillerato TV, orientado a un público, en principio, más adulto, TVE se dirigía a una audiencia más heterogénea. Bachillerato $T V$ sólo duró un curso completo (1963-1964) en antena aunque en 1965 se recuperó durante unos meses (de marzo a mayo, en la misma situación de parrilla). García Jiménez atribuye el relativo fracaso en televisión de esta experiencia al carácter "ultraconservador de las enseñanzas impartidas y a la escasa sensibilidad de sus responsables hacia la televisión" (1980:313): TVE se limitaba a emitir los productos que le suministraba el Centro, independientemente de si eran adecuados para el medio o no.

En 1965 los programas educativos se limitarán a los tres meses de Bachillerato $T V$ y a la inclusión de lecciones diarias y muy cortas de inglés entre las 19:30 y las 20:00. También aparece el programa Protección Escolar (y Protección de juventud, en 1966), en la franja de tarde que parece versar sobre los derechos de la infancia, pero dada su escaso recorrido en parrilla y su duración (10 minutos) es posible que sólo fuera una forma de complementar la programación. Esto mismo ocurre con Los números, emitido en 1966, de entre 10 y 13 minutos de duración en franja de tarde. Sólo hubo seis emisiones entre el 14 de enero y el 18 de marzo y debido a su título intuimos que el contenido versaba sobre las matemáticas. 
El último programa clasificado como educativo es Imágenes para saber, que según la el Informe Marco de la Televisión Educativa de 1996, fue realizado con motivo de la Campaña Sistemática de Alfabetización de Adultos y que comenzó a emitirse en octubre de 1966 de lunes a miércoles, en franja de tarde (19:40 a 20:10 horas) y se prolongaría hasta 1967. "Con esta experiencia se crea por primera vez un equipo de trabajo formado por profesores y asesores del Ministerio de Educación y Ciencia y profesionales de la televisión, Los guiones didácticos para la explotación de este material audiovisual se publicaban mensualmente, con el fin de que los profesores interesados pudieran utilizarlos en el centro escolar" (Informe Marco, 1996:10). El 10 de octubre de 1966 se inician las emisiones de este programa, pero habrá que esperar hasta más de un mes después de su estreno para encontrar un reportaje en Tele Radio (número 466 del 4 de diciembre de 1966, páginas 10-13), en el que se asegura que el espacio colabora con la Campaña Nacional de Alfabetización que sostiene el Ministerio de Educación y Ciencia. A lo largo del artículo se explica cómo esta emisión pretende adoptar las nuevas técnicas de enseñanza en el campo de la alfabetización:

"Pretenden enseñar la lectura por un camino casi ideogramático: cada palabra tiene una forma concreta de escritura, un signo total, un ideograma y sólo más tarde adivinaremos que este signo total está compuesto por determinadas letras. [...] En resumen: el niño o el adulto pueden aprender hoy a leer sin saber las letras" (Revista Tele Radio, $\mathrm{n}^{\circ}$ 466, 4 de diciembre de 1966, pp. 10-13).

El programa está centrado en cuarenta palabras. En cada emisión se plantea una nueva que incluye respecto de la anterior, una única letra y todo el espectador aprenderá primero a 'configurar' la palabra oral y escrita, a 'reconocer' cual es la estructura de esa palabra, qué letras la forman y por último a 'contextualizarla': descubrir el significado de la palabra escrita.

La parte del reportaje que tiene más interés para este artículo en concreto es la que se refiere a las explicaciones que da a los lectores respecto a su ubicación en parrilla:

"Con frecuencia, y en casi todas las televisiones del mundo, se ha planteado la cuestión de si los programas de alfabetización debían o no debían ser emitidos en horas de audiencia normal por las cadenas nacionales o por el contrario, ser ofrecidas en circuito cerrado a los teleclubs, escuelas y cuarteles a quienes pudiera interesar. :a respuesta ha sido la de optar por la primera selección, pero siempre haciendo que el programa pueda interesar, por contenido didáctico y televisivo, al mayor número de espectadores posible y no sólo a los de mayor o menor grado de analfabetismo" (Revista Tele Radio, $\mathrm{n}^{\circ}$ 466, 4 de diciembre de 1966, pp. 10-13).

Es decir, que desde TVE pretendían que este programa y por extensión, todos los programas dirigidos a un público objetivo concreto, como en el caso de los programas de corte educativo, interesaran al mayor número de espectadores posible. Por eso estaban situados en franjas horarias muy pobladas.

\section{Conclusiones}

El término educativo tiene un marco de significados que está estrechamente vinculado con la realidad social de cada momento. El periodo cronológico de este estudio tiene 
por eso fuertes implicaciones para entender el significado de la televisión educativa: tanto en sus contenidos, como en lo que se consideraba su público objetivo. Es básico en este aspecto la importancia que tenía la alfabetización de la población adulta para las autoridades. Los esfuerzos aún no suficientes en intensidad del régimen -con mayor o menor acierto- para asegurar la total escolarización de los españoles en edad escolar, constituían una mejora que se transmitiría al futuro; pero los restos de quienes carecían de la capacidad mínima de leer y escribir constituían un problema de presente de difícil solución.

Este contexto es fundamental para comprender los intentos de TVE en su programación educativa. $\mathrm{Y}$ es que efectivamente una parte relativamente importante de esta Televisión Educativa estaba dirigida a adultos. Esta tendencia se pone de manifiesto al estudiar las franjas horarias en que emiten muchos de estos programas: por ejemplo, los programas Bachillerato TV, Academia TV e Imágenes para saber se emiten (por ese orden) de 19:03 a 19:30, de 18:00 a 18:30 y de 19:40 a 20:10.

Sus títulos además constituyen una llamada a esa tarea de mejora. El bachillerato constituía aún en esos años la barrera que separaba culturalmente a las clases medias altas de las medias bajas o bajas. Conformaba un periodo de la vida en el que los niños de 10 años iniciaban la larga preparación (siete años, dos reválidas y una prueba de madurez tras la que se accedía a la universidad) para los estudios superiores universitarios o, para quienes no concluían tan largo recorrido, los de grado medio (los diversos peritajes, maestrías profesionales en comercio o en otras profesiones: desde la optometría hasta las escuelas de artes y oficios superiores).

El bachillerato constituía a la vez la barrera que separaba de la mejor preparación la posibilidad de ascenso social para quienes vivían en las grandes ciudades y una prueba de una formación que permitía acceder a puestos de relativa buena posición en oficinas o en la administración pública. Por eso ese título abría una puerta a la esperanza. Desde luego no era un modo de conseguir el ansiado bachillerato para los adultos; pero sí abría una puerta a la esperanza de mejora. En fin, una suerte de bachillerato de segunda categoría, una segunda oportunidad a quienes no habían podido acceder a él. El segundo título-Academia $T V$ - también conectaba con algo familiar. El lugar, los locales, en que esa formación se impartía, normalmente en horarios de tarde y noche- para todos aquellos que querían mejorar en su formación (desde la preparación de la entrada en la universidad hasta el aprendizaje siempre presente de los idiomas francés o inglés en un país de monóglotas- de la taquigrafía, la mecanografía, la contabilidad, etc.)

Fuera del acierto de los títulos no parece que los programas dirigidos a adultos tuvieran demasiado éxito. Su permanencia en antena fue escasa: Imágenes para saber duró un año, con un total de 131 emisiones, Academia $T V$ dos años con 308 emisiones y Bachillerato TV otros dos años pero con tan sólo 92 emisiones. Además su horario, aunque no fuera para niños tampoco era especialmente bueno para el público al que se dirigían. Tampoco el prime time nocturno podía orientarse a un público necesariamente limitado.

Esa primera contradicción se sumaba a otra anterior: quienes hasta 1963-65 podían comprar un televisor tenían ya un status social bien distinto del teórico público obje- 
tivo de estos programas de mejora cultural para adultos. Quienes hubieran disfrutado con estos programas no disponían entonces de televisor. Por otra parte, como ya señaló Jesús García Jiménez los programas educativos no eran un tipo de emisiones muy generalizadas, y es probable que no calaran entre el público debido a que los contenido no estaban en sintonía con el medio que los difundía. No se adecuaban al canal: la televisión, y eso hacía que los receptores no fueran, valga la redundancia, tan receptivos como sí lo eran con programas genuinamente televisivos como las series americanas. La única excepción a esto parece ser Imágenes para saber, en la que sus creadores pusieron un firme interés en explotar las ventajas de los rayos catódicos, aunque parece que ese mismo afán por llegar al mayor número de gente posible, como expresaban en su declaración de intenciones de Tele Radio, esa generalidad es lo que hizo que el esfuerzo no calara más hondo.

Muy probablemente este interés por la programación educativa estuviera influida por las experiencias radiofónicas anteriores. Quizá también se tuvo el sueño de que la televisión lograría aquello en lo que el cine había fracasado finalmente. Estos aspectos han de ponerse en relación con la cultura de los directivos y realizadores de TVE y las posibilidades reales de un medio que estaba dando sus primeros pasos no solo en España. A pesar de los numerosos programas enmarcados en este subgénero, sólo se han encontrado dos experiencias que se pueden catalogar como antecedentes claros de la Televisión Escolar: Imágenes para saber y Bachillerato TV. El resto son apuestas personales y personalistas de un ideal como en el caso de Universidad TV, pero que no pueden catalogarse como enseñanza reglada por la imposibilidad de que los espectadores aprovecharan las lecciones debido a diferentes factores como la gran amplitud de temas tratados, o la falta de una estructura que coordinada la experiencia y a los profesionales, como en Escuela $T V$. Una excepción a esto son los cursos de idiomas: avalados e impartidos por profesionales, parece que realmente pretendían dirigirse a un público amplio y que éste consiguiera dominar las normas más elementales para comunicarse. La continuidad de estos programas en antena constituye un primer elemento de valoración acerca de su audiencia y utilidad, aunque la falta de documentación relativa a ellos hace que sea imposible determinar hoy en día el alcance que tuvieron y si realmente eran seguidos por los espectadores de una forma receptiva.

La puesta en marcha de una programación educativa eficaz hubiera exigido que el Ministerio de Educación y el de Información (donde estaba integrada TVE) hubieran colaborado de una manera coordinada. Al menos algunos organismos específicos de ambos. No fue así. En parte por la tradición inveterada de los gobiernos españoles en los que cada ministro tenía una enorme autonomía en su departamento. Quizá más aún en los gobiernos de Franco. Tampoco la misión era fácil -como demuestran las experiencias, malas, por lo general, de las demás televisiones estatales europeas en países con problemas similares a los españoles, en este campo.

\section{Referencias}

DE AGUILERA GAMONEDA, Joaquín (1975): Dimensión y sistema de la televisión educativa. Madrid, Ritmo Universitario. 
DE AGUILERA GAMONEDA, Joaquín (1980): La educación por televisión: un servicio público desatendido. Pamplona, Ediciones Universidad de Navarra, S. A.

ÁLVAREZ, Jesús Timoteo (coord., 1989): Historia de los medios de comunicación en España: Periodismo, imagen y publicidad (1900-1990). Barcelona, Ariel.

BAGUET, Josep Maria (1975): 18 años de TVE. Barcelona, Diáfora.

BAGUET, Josep Maria (1992): Historia de la televisión en España, (1956-1975) [Ed. micrográfica]. Bellaterra, Publicacions de la Universitat Autònoma de Barcelona.

BUSTAMANTE, Enrique (2006): Radio y televisión en España: Historia de una asignatura pendiente de la democracia. Barcelona, Gedisa.

CABRERO ALMENARA, Julio (1994): "Retomando un medio: la televisión educativa", en CMIDE-SAV: Medios de comunicación, recursos y materiales para la mejora educativa, Sevilla, CMIDE del Excmo. Ayuntamiento de Sevilla y SAV de la Universidad de Sevilla, 161-193.

CARRERAS LARIO, Natividad (2012): TVE en sus inicios: Estudio sobre la programación. Madrid, Fragua.

CEBRIÁN HERREROS, Mariano (2004): Modelos de televisión: Generalista, temática y convergente con internet. Barcelona, Paidós.

CONTRERAS, José Miguel y PALACIO, Manuel (2001): La programación de televisión. Madrid, Síntesis.

DÍAZ, Lorenzo (1994): La televisión en España, 1949-1995. Madrid, Alianza editorial.

DE GABRIEL, Narciso (1997): “Alfabetización, semialfabetización y analfabetismo en España (1860-1991)”, en Revista Complutense de Educación, vol. 8, nº 1, 1997. Madrid, Servicio de Publicaciones de la Universidad Complutense.

GARCÍA JIMÉNEZ, Jesús (1980): Radiotelevisión y política cultural en el franquismo. Madrid, C.S.I.C., Instituto Balmes de Sociología.

GARCÍA MATILLA, Agustín (2004): Una televisión para la educación: La utopía posible ( $2^{\mathrm{a}}$ ed. ed.). Barcelona, Gedisa.

GÓMEZ-ESCALONILLA MORENO, Gloria (2003): Programar televisión: Análisis de los primeros cuarenta años de programación televisiva en España. Madrid, Dykinson.

LACALLE, Charo (2008): El discurso televisivo sobre la inmigración: Ficción y construcción de identidad. Barcelona, Omega.

MERINO Belmonte, Justo (1983): Televisión educativa en España : (historia, metodología y planificación). Madrid, Universidad Complutense de Madrid.

MINISTERIO DE EDUCACIÓN Y CULTURA (1996): Informe Marco sobre la Televisión Educación en España. Madrid, MEC, 1996.

MUNSÓ CABÚS, Joan (2001): La otra cara de la televisión: 45 años de historia y política audiovisual. Barcelona, Flor del Viento Ediciones. 
PALACIO, Manuel (2001): Historia de la televisión en España. Barcelona, Gedisa. PÉREZ TORNERO, José Manuel (1994): El desafio educativo de la televisión. Barcelona, Paidós.

RODRÍGUEZ PASTORIZA, Francisco (2003): Cultura y televisión. Una relación de conflicto. Madrid, Gedisa.

RUEDA LAFFOND, José Carlos y CHICHARRO MERAYO, María del Mar (2006): La televisión en España, 1956-2006: Política, consumo y cultura televisiva. Madrid, Fragua.

SERRANO, Marta y OJEDA CASTAÑEDA, Gerardo.: "Televisión educativa y audiencias: una aproximación conceptual. Tecnología y comunicación educativas. No44. 2008.

TELEDIARIO: Programa semanal de la TVE. Madrid. Consulta de todos los números de 1958 y 1959).

TELE RADIO: Revista Semanal de TVE-RNE. Barcelona, Madrid. Consulta de todos los números comprendidos entre 1960 y 1966).

VÁZQUEZ MONTALBÁN, Manuel (1973): El libro gris de televisión española. Madrid, Edic. 99.

VIÑAO, Antonio: La alfabetización en España: un proceso cambiante de un mundo Multiforme. EFORA. Vol. 3. Marzo 2009. 